\title{
MELHORIA DA ESTRUTURA DE UM LATOSSOLO POR SISTEMAS DE CULTURAS EM PLANTIO DIRETO NOS CAMPOS GERAIS DO PARANÁ(1)
}

\author{
Vagner Lopes Da-Silva(2), Jeferson Dieckow ${ }^{(3)}$, José Elias Mellek(2), \\ Rudimar Molin $^{(4)}$, Nerilde Favaretto(3), Volnei Pauletti ${ }^{(5)} \&$ Fabiane \\ Machado Vezzani ${ }^{(5)}$
}

\begin{abstract}
RESUMO
O plantio direto de qualidade depende de um manejo adequado do solo que promova melhorias em sua estrutura. Isso está associado ao sistema de culturas adotado. O objetivo deste trabalho foi avaliar a contribuição de sistemas de culturas de longo prazo (18 anos) na qualidade estrutural de um Latossolo Vermelho mesoférrico argiloso sob plantio direto nos Campos Gerais do Paraná. Foram avaliados cinco sistemas de culturas: trigo-soja [Tr-So]; aveia-milho-trigo-soja [Av-Mi-Tr-So]; ervilhaca-milho-trigo-soja [Er-Mi-Tr-So]; azevém-milho-azevém-soja [Az-Mi-Az-So]; e alfafa-milho [Alf-Mi]. Amostras de solo foram coletadas nas camadas de 0-5, 5-10 e 10-20 cm, em anéis volumétricos e em blocos com estrutura preservada. Na camada de $0-5 \mathrm{~cm}$, as menores densidades de solo tenderam a ocorrer nos sistemas Av-Mi-Tr-So $\left(0,96 \mathrm{Mg} \mathrm{m}^{-3}\right)$ e Er-Mi-Tr-So $\left(0,93 \mathrm{Mg} \mathrm{m}^{-3}\right)$. Nas camadas de $5-10$ e $10-20 \mathrm{~cm}$, as menores densidades de solo ocorreram no sistema Alf-Mi (1,14 e $1,17 \mathrm{Mg} \mathrm{m}^{-3}$, respectivamente). Tendência coerente foi observada para a macroporosidade, que na camada superficial foi maior nos sistemas Av-Mi-Tr-So $\left(0,29 \mathrm{~m}^{3} \mathrm{~m}^{-3}\right)$ e Er-Mi-Tr-So $\left(0,30 \mathrm{~m}^{3} \mathrm{~m}^{-3}\right)$ e, nas camadas de 5-10 e 10-20 cm, tendeu a ser maior no sistema Alf-Mi $\left(0,19 \mathrm{~m}^{3} \mathrm{~m}^{-3}\right)$. A microporosidade não apresentou tendência clara entre os sistemas. A
\end{abstract}

(1) Parte da Dissertação de Mestrado do primeiro autor apresentada ao Programa de Pós-Graduação em Ciência do Solo, Universidade Federal do Paraná - UFPR. Recebido para publicação em 28 de junho de 2011 e aprovado em 21 de março de 2012.

(2) Engenheiro-Agrônomo, Mestre em Ciência do Solo, Universidade Federal do Paraná - UFPR. Rua dos Funcionários 1540, CEP 80035-050 Curitiba (PR).E-mails: vagnerlopess@yahoo.com.br; eemellek@yahoo.com.br

(3) Professor Adjunto, Departamento de Solos e Engenharia Agrícola, UFPR. Bolsista PQ CNPq. E-mails: jefersondieckow@ufpr.br; nfavaretto@ufpr.br

(4) Pesquisador, Área de Fitotecnia, Fundação ABC para Assistência e Divulgação Técnica Agropecuária. Caixa Postal 1003, CEP 84166990 Castro (PR). E-mail: molin@fundacaoabc.org.br

(5) Professor Adjunto, Departamento de Solos e Engenharia Agrícola, UFPR. E-mails: vpauletti@ufpr.br; vezzani@ufpr.br 
condutividade hidráulica saturada teve relação direta com a macroporosidade, com Er-Mi-Tr-So apresentando o maior valor na camada de 0-5 cm (224 mm h-1)

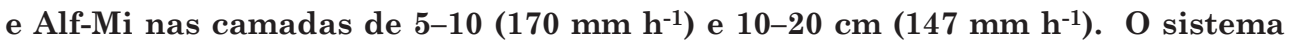
Er-Mi-Tr-So apresentou o menor diâmetro médio ponderado úmido de agregados na camada de 0-5 cm (2,39 mm), e o Tr-So, o maior (3,04 mm). Os maiores valores de resistência mecânica do solo à penetração foram observados no sistema TrSo, superando 1,5 MPa na camada de 7,5 a $22,5 \mathrm{~cm}$ de profundidade. $O$ sistema Alf-Mi apresentou o menor grau de compactação (0,2 $\mathrm{MPa} \mathrm{cm})$. Os resultados são atribuídos, principalmente, à ação das raízes das espécies que constituem os sistemas de culturas e à intensidade de tráfego de máquinas em cada sistema. Considerando a camada de 0-20 cm como um todo, o sistema semiperene Alf-Mi possui maior capacidade de promover melhorias na qualidade estrutural do solo, em comparação aos sistemas baseados em cultivos de espécies anuais. Sistemas bianuais de rotação, baseados em plantas de cobertura como aveia-preta ou ervilhaca, promovem melhorias na qualidade estrutural do solo em relação à sucessão trigo-soja.

Termos de indexação: rotação de culturas, leguminosas, índice de cone, agregação do solo, densidade, porosidade.

\section{SUMMARY: IMPROVEMENT OF AN OXISOL STRUCTURE BY NO-TILL CROPPING SYSTEMS IN THE REGION OF CAMPOS GERAIS, PARANÁ}

The quality of no-tillage systems depends on an adequate soil management that promotes soil structure improvements. This is associated to the cropping system adopted. This study investigated the effect of long-term no-tillage systems (18years) on the structural quality of a sandy-clay to clay Oxisol (Latossolo Vermelho) in the region of Campos Gerais, Paraná, Brazil. Five cropping systems were assessed: wheat-soybean [Wt-So], black oatmaize-wheat-soybean [Ot-Mz-Wt-So], vetch-maize-wheat-soybean [Vt-Mz-Wt-So], ryegrassmaize-ryegrass-soybean [Rg-Mz-Rg-So]; and alfalfa-maize [Alf-Mz]. Soil was sampled from the layers 0-5, 5-10 and 10-20 cm, in cylinders and in blocks with undisturbed structure. In the 0-5 cm layer, bulk density was lowest in the Ot-Mz-Wt-So $\left(0.96 \mathrm{Mg} \mathrm{m}^{-3}\right)$ and Vt-MzWt-So systems $\left(0.93 \mathrm{Mg} \mathrm{m}^{-3}\right)$. In the 5-10 and 10-20 $\mathrm{cm}$ layers, the bulk density tended to be lowest in Alf-Mz systems (1.14 and $1.17 \mathrm{Mg} \mathrm{m}^{-3}$, respectively). A similar trend was observed for macroporosity, which in the top layer was greater in Ot-Mz-Wt-So $\left(0.29 \mathrm{~m}^{3} \mathrm{~m}^{-3}\right)$ and $V t$ - $M z$-Wt-So $\left(0.30 \mathrm{~m}^{3} \mathrm{~m}^{-3}\right)$ and in the 5-10 and 10-20 $\mathrm{cm}$ layers tended to be greater in the Alf-Mz system $\left(0.19 \mathrm{~m}^{3} \mathrm{~m}^{-3}\right)$. No clear trend was observed for microporosity. The saturated hydraulic conductivity was directly related with macroporosity, and was highest for Vt-Mz-Wt-So in the 0-5 $\mathrm{cm}$ layer (224 $\left.\mathrm{mm} \mathrm{h}^{-1}\right)$ and Alf-Mz in the layers 5-10 (170 $\left.\mathrm{mm} \mathrm{h}^{-1}\right)$ and 10-20 $\mathrm{cm}\left(147 \mathrm{~mm} \mathrm{~h}^{-1}\right)$. In the Vt-Mz-Wt-So system, the mean weight diameter of aggregates was lowest in the $0-5 \mathrm{~cm}$ layer $(2.39 \mathrm{~mm})$ and highest $(3.04 \mathrm{~mm})$ in the Wt-So. The highest cone index values were observed in the Wt-So system, with over $1.5 \mathrm{MPa}$ in the $7.5-22.5 \mathrm{~cm}$ layer. The compaction degree was lowest in the Alf-Mz system $(0.2 \mathrm{MPa} \mathrm{cm})$. Results were attributed mainly to the role of the crop roots of the systems and to the intensity of machinery traffic. Considering the 0-20 cm layer as a whole, the capacity to promote soil structural quality improvements was greater for the semi-perennial Alf-Mz system than for systems based on annual species. Bi-annual rotation systems, based on cover crops such as black oat and vetch, promote soil structural quality improvements compared to the wheat - soybean succession.

Index terms: Crop rotation, legumes, cone index, soil aggregation, density, porosity. 


\section{INTRODUÇÃO}

A qualidade da estrutura do solo é fundamental para o suprimento de água, nutrientes e oxigênio às raízes, além de proporcionar condições de resistência mecânica favoráveis ao crescimento radicular (Tormena et al., 1999). Melhorias na estrutura do solo, principalmente na estabilidade de agregados, são obtidas com a conversão do sistema convencional de preparo em sistemas conservacionistas, como o plantio direto (Carpenedo \& Mielniczuk, 1990; Campos et al., 1995; Silva \& Mielniczuk, 1997). Contudo, com a ampla adoção do sistema plantio direto no Sul do Brasil, o desafio atual é melhorar ainda mais a qualidade da estrutura do solo pela adoção de sistemas de rotação de culturas, utilizando-se dos benefícios advindos das plantas em termos de adição de resíduos culturais e de ação das raízes, seja no enredamento, por raízes fasciculadas, como na abertura de canais, por raízes pivotantes.

Sistemas de culturas perenes ou semiperenes, baseados, principalmente, em pastagens, possuem grande potencial em melhorar a estrutura do solo em comparação aos sistemas anuais (Vezzani \& Mielniczuk, 2011). A manutenção do sistema radicular vivo de um ano para o outro e sua contínua e gradual renovação possibilitam que as raízes sejam mais eficazes na agregação pela ação mecânica de enredamento (Greenland, 1971), pela ação de mucilagens de polissacarídeos (Tisdall \& Oades, 1982) e pela ação de ciclos de umedecimento e secamento ao nível de rizosfera (Bradfield, 1937; Greenland, 1971). A maior estabilidade estrutural promovida pela alfafa em particular pode estar associada com a liberação de polissacarídeos pelas raízes, na forma de mucilagens (Reid \& Goss, 1981). Essas melhorias estruturais com o cultivo de alfafa refletem-se também no aumento da taxa de infiltração de água no solo, devido à formação de macroporos a partir de canais de raízes (Meek et al., 1989; Rasse et al., 2000).

$\mathrm{O}$ azevém tem sido reportado também como uma importante cultura para a agregação do solo melhor inclusive que algumas leguminosas, como o trevo-branco -, e isso tem sido atribuído ao sistema extensivo de raízes finas e às hifas de micorrizas associadas ao azevém (Tisdall \& Oades, 1979). O cultivo de azevém no inverno para a produção de feno, antecedendo o cultivo de soja ou milho no verão, é uma prática comum nas propriedades da região dos Campos Gerais, que conciliam a atividade agrícola com a produção leiteira em confinamento, e pode ser uma estratégia interessante para a qualidade da estrutura do solo.

O cultivo de plantas de cobertura de inverno é uma estratégia que também contribui para a melhoria da qualidade da estrutura do solo.
Num Argissolo franco-argiloarenoso, Paladini \& Mielniczuk (1991) observaram melhorias significativas no estado de agregação, especialmente nas classes maiores que $2 \mathrm{~mm}$ de diâmetro, com o cultivo do consórcio aveia-preta + ervilhaca em substituição ao pousio no inverno, e atribuíram isso à ação mecânica das raízes de aveia e à provável contribuição da ervilhaca para o aumento do teor de matéria orgânica. Tendência semelhante foi observada em outro Argissolo, porém de textura franco-arenosa, onde sistemas de culturas com gramíneas e leguminosas possibilitaram maior agregação em relação à sucessão pousio invernalmilho ou ao solo descoberto (Wohlenberg et al., 2004). A adoção de sistemas de culturas baseados em rotações com uso de aveia-preta e ervilhaca no inverno e milho no verão reduziu a densidade, aumentou a condutividade hidráulica saturada (Albuquerque et al., 1995) e tendeu a melhorar a agregação (Campos et al., 1995) de um Latossolo argiloso sob plantio direto, em comparação à sucessão trigo-soja na região agrícola do Planalto Gaúcho. Isso foi atribuído ao menor tráfego de máquinas no sistema com plantas de cobertura, à ação mais eficaz do sistema radicular dessas plantas, sobretudo da aveia-preta, e ao aumento no teor de carbono orgânico, em comparação com a sucessão trigo-soja (Albuquerque et al., 1995; Campos et al., 1995).

Por outro lado, num estudo conduzido por seis anos em Cambissolo Húmico do Planalto Catarinense sob plantio direto, não foram observadas melhorias na estrutura do solo com a adoção da rotação trianual feijão-aveia-milho-nabo-soja-ervilhaca em relação à sucessão milho-ervilhaca, pois a densidade, macroporosidade, microporosidade e o diâmetro médio de agregados do solo foram similares entre esses dois sistemas (Bertol et al., 2004). Entretanto, seis anos mais tarde, melhorias na estrutura foram observadas no sistema em sucessão (Andrade et al., 2010), e isso pode ser explicado pelo fato de o milho - que possui sistema radicular mais abundante e, por isso, mais eficaz em melhorar a estrutura ser cultivado todos os anos, enquanto no sistema em rotação o milho foi cultivado a cada três anos, intercalado por feijão e soja, que possuem raízes menos abundantes. Genro-Junior et al. (2004, 2009), em Latossolo Vermelho argiloso, também não verificaram redução na resistência mecânica do solo à penetração com sistemas de rotação baseados em plantas de cobertura de verão (guandu e crotalária).

O objetivo deste estudo foi avaliar a capacidade de sistemas de culturas baseados em plantas de cobertura de inverno (aveia-preta ou ervilhaca) ou forrageiras para feno (azevém ou alfafa) para melhorar a qualidade da estrutura de um Latossolo Vermelho (densidade, porosidade, condutividade 
hidráulica, diâmetro de agregados e resistência à penetração) manejado sob plantio direto por 18 anos na região dos Campos Gerais do Paraná.

\section{MATERIAL E MÉTODOS}

\section{Área experimental e coleta de amostras de solo}

O trabalho foi conduzido a partir de um experimento de campo de longa duração (18 anos), incluindo sistemas de culturas em plantio direto, instalado na área experimental da Fundação ABC para Assistência e Divulgação Técnica Agropecuária, no município de Ponta Grossa - PR (2500' 42 ” S, $50^{\circ} 09^{\prime} 13^{\prime}$ 'W e altitude de $877 \mathrm{~m}$ ). O solo foi classificado como Latossolo Vermelho distrófico típico, mesoférrico (Embrapa \& FundaçãoABC , 2001), de textura argilosa na camada de 0-20 cm (400 g kg-1 de argila, $150 \mathrm{~g} \mathrm{~kg}^{-1}$ de silte e $450 \mathrm{~g} \mathrm{~kg}^{-1}$ de areia). A declividade da área era de $3 \%$. O clima da região é subtropical (Cfb, Köppen), com temperaturas médias mensais variando de $11-12{ }^{\circ} \mathrm{C}$ no mês mais frio (julho) a $21-22{ }^{\circ} \mathrm{C}$ no mês mais quente (janeiro) e precipitação pluvial média anual entre 1.700 e $1.800 \mathrm{~mm}$, bem distribuídos ao longo do ano (IAPAR, 1984).

O experimento foi instalado no inverno de 1989 e era constituído por sete sistemas de culturas em plantio direto distribuídos em parcelas de $7,0 \times 10,5 \mathrm{~m}$, de acordo com o delineamento de blocos ao acaso com quatro repetições. Foram selecionados e avaliados cinco sistemas de culturas: (i) sucessão trigo (Triticum aestivum L.) - soja (Glycine max L.) [Tr-So]; (ii) rotação bianual de aveia-preta (Avena strigosa Schreb.) - milho (Zea mays L.) - trigo - soja [Av-Mi-Tr-So], sendo a aveia-preta para cobertura do solo no inverno e dessecada antes do plantio do milho; (iii) rotação bianual de ervilhaca (Vicia sativa L.) - milho - trigo - soja [Er-Mi-Tr-So], sendo a ervilhaca para cobertura do solo no inverno e dessecada antes do plantio do milho; (iv) rotação bianual de azevém (Lolium multiflorum L.) - milho - azevém - soja [Az-Mi-Az-So], representando um sistema integrado de produção de feno (azevém) e grão (milho e soja); e (v) alfafa (Medicago sativa L.) para a produção de feno, com um cultivo de milho a cada três anos [Alf-Mi].

Amostras de solo foram coletadas em setembro de 2007, em duas trincheiras dispostas diagonalmente em cada parcela, tendo como dimensões aproximadas $60 \mathrm{~cm}$ de comprimento, $40 \mathrm{~cm}$ de largura e $30 \mathrm{~cm}$ de profundidade. Em cada trincheira, dois tipos de amostra do solo foram coletados nas camadas de 0-5, 5-10 e 10-20 cm: a) em anéis volumétricos de 5,6 cm de diâmetro e 3,1 cm de altura, para as avaliações de densidade do solo, macroporosidade, microporosidade e condutividade hidráulica; e b) em blocos com estrutura preservada de $10 \mathrm{~cm}$ de largura por $15 \mathrm{~cm}$ de comprimento, com a altura correspondente à espessura da camada amostrada, para avaliação do diâmetro médio ponderado úmido dos agregados. Na época da coleta, o experimento estava cultivado com trigo (em Tr-So), aveia-preta (em Av-Mi-Tr-So), ervilhaca (em Er-Mi-Tr-So), azevém (em Az-Mi-Az-So) e alfafa (em Alf-Mi).

\section{Densidade, microporosidade, macroporosidade e condutividade hidráulica saturada do solo}

As amostras de solo contidas nos anéis volumétricos, após ajuste ao volume do anel, foram saturadas com água por um período de $12 \mathrm{~h}$ e, posteriormente, submetidas a uma tensão de $6 \mathrm{kPa}$ $(60 \mathrm{~cm})$ por $24 \mathrm{~h}$ para a drenagem dos macroporos, em mesa de tensão (Oliveira, 1968), e pesadas. A microporosidade foi considerada como equivalente ao volume de água contido na amostra após as $24 \mathrm{~h}$ de tensão. A macroporosidade foi calculada pela diferença entre porosidade total e microporosidade. A porosidade total foi calculada a partir da densidade do solo e densidade de partículas, esta assumida como sendo $2,65 \mathrm{Mg} \mathrm{m}^{-3}$. A densidade do solo foi determinada após secagem a $105{ }^{\circ} \mathrm{C}$.

Após retirada das amostras da mesa de tensão e antes da secagem a $105^{\circ} \mathrm{C}$, elas foram colocadas em permeâmetro de carga constante (Embrapa, 1997) para determinação da condutividade hidráulica saturada. A altura da lâmina de água sobre o topo do anel contendo a amostra foi ajustada em $20 \mathrm{~mm}$, com auxílio de um anel vazio sobreposto ao anterior e preso com fita adesiva. As leituras do volume de água que passava pela amostra de solo foram medidas a cada hora, até a estabilização, que, geralmente, ocorreu em torno de $8 \mathrm{~h}$ após o início da avaliação. A condutividade hidráulica saturada foi calculada por meio da equação de Darcy, considerando-se os dois ou três últimos pontos estáveis de avaliação do volume de água que passava pela amostra (Embrapa, 1997).

\section{Diâmetro médio ponderado úmido (DMPu) de agregados}

As amostras coletadas em blocos com estrutura preservada foram manual e cuidadosamente desagregadas em unidades com tamanho inferior a $8 \mathrm{~mm}$, sendo posteriormente secas ao ar e na sombra. A peneiração úmida foi feita segundo adaptações de Tisdall et al. (1978) e Carpenedo \& Mielniczuk (1990). Aproximadamente $25 \mathrm{~g}$ de agregados foram umedecidos por capilaridade, por 
um período de $12 \mathrm{~h}$, e transferidos para o topo de um conjunto de peneiras de 4,00, 2,00,1,00, 0,50 e $0,25 \mathrm{~mm}$. Os agregados foram separados em seis classes de tamanho $(>4,00,4,00-2,00,2,00-1,00$, $1,00-0,50,0,50-0,25$ e $<0,25 \mathrm{~mm})$ por meio de movimentos oscilatórios verticais desse conjunto de peneiras, dentro de um recipiente contendo água, numa amplitude de $3 \mathrm{~cm}$, com 42 oscilações/ min e durante 15 min (adaptação do aparelho de Yoder). Os agregados retidos em cada peneira foram transferidos para copos plásticos, secos a $55^{\circ} \mathrm{C}$ e pesados, para posterior cálculo do DMPu (Kemper \& Rosenau, 1986).

\section{Resistência mecânica do solo à penetração (RP)}

A avaliação da RP foi realizada em campo, em maio de 2008, antes da semeadura das culturas de inverno, em 10 pontos por parcela. Foi utilizado um penetrômetro digital de cone (Spectrum Technologies, Inc.), com a haste introduzida até a profundidade de $40 \mathrm{~cm}$ e leituras de índice de cone em intervalos de $2,5 \mathrm{~cm}$.

Considerou-se 1,5 $\mathrm{MPa}$ como o valor crítico de RP. Em geral, considera-se o valor de 2,0 $\mathrm{MPa}$ como crítico (Taylor et al., 1966), porém Cintra \& Mielniczuk (1983) observaram redução de $50 \%$ na elongação de raízes de soja com valores de $R P$ de 1,1 MPa. Levando-se em conta esses dois trabalhos, optou-se por um valor intermediário de 1,5 MPa como crítico para a RP. Convém ressaltar, no entanto, que a definição do valor crítico de RP ainda é uma discussão em andamento (Klein \& Camara, 2007).

A partir dos valores de RP, calculou-se o grau de compactação, dado pela integração da área do gráfico da $R P \times$ profundidade, para as camadas que apresentaram $\mathrm{RP}$ superior a 1,5 $\mathrm{MPa}$.

\section{Análise estatística}

Os resultados foram submetidos à análise de variância e ao teste de médias de Tukey $(p<0,10)$, comparando-se os sistemas de cultura dentro de cada camada. Para realização da análise estatística, utilizou-se o software SASM-Agri (Canteri et al., 2001) e o pacote estatístico da Microsoft Office Excel 2007.

\section{RESULTADOS E DISCUSSÃO}

\section{Densidade do solo, macroporosidade, microporosidade e condutividade hidráulica saturada}

A densidade do solo na camada superficial de $0-5 \mathrm{~cm}$ tendeu a ser menor nos sistemas com plantas hibernais de cobertura $\left(0,96 \mathrm{Mg} \mathrm{m}^{-3} \mathrm{em} \mathrm{Av}-\mathrm{Mi}\right.$-Tr-So e $0,93 \mathrm{Mg} \mathrm{m}^{-3}$ em Er-Mi-Tr-So), embora não tenha diferido significativamente dos demais sistemas (Figura 1a). A macroporosidade, como esperado, apresentou tendência inversa, com maiores valores na camada de $0-5 \mathrm{~cm}$ para os sistemas Av-MiTr-So $\left(0,29 \mathrm{~m}^{3} \mathrm{~m}^{-3}\right)$ e Er-Mi-Tr-So $\left(0,30 \mathrm{~m}^{3} \mathrm{~m}^{-3}\right)$ (Figura 1b). Essa tendência de melhoria na condição estrutural da camada de $0-5 \mathrm{~cm}$ com o cultivo de aveia-preta ou ervilhaca em relação à sucessão TrSo está associada à ação mecânica das raízes dessas espécies, pois, por ocasião da coleta e preparo das respectivas amostras de solo, a maior abundância de raízes nesses sistemas e nessa camada superficial era visualmente perceptível. Além disso, a intensidade de tráfego nesses sistemas de rotação foi menor que na sucessão Tr-So, por não haver tratos culturais e colheita de grãos, quando do cultivo de plantas de cobertura.

Os benefícios de sistemas de culturas baseados no cultivo de aveia-preta e ervilhaca para cobertura do solo no inverno, no sentido de reduzir a densidade e aumentar a macroporosidade em Latossolo sob plantio direto, em comparação à sucessão trigosoja, já haviam sido destacados por Albuquerque et al. (1995), os quais também atribuíram as causas desses benefícios à ação mais eficaz do sistema radicular dessas plantas, especialmente da aveiapreta, ao aumento no teor de carbono orgânico e ao menor tráfego de máquinas no sistema com plantas de cobertura, em relação ao sistema trigo-soja.

Nas camadas de 5-10 e 10-20 cm, foi o sistema semiperene de Alf-Mi que apresentou os menores valores de densidade do solo (1,14 e 1,17 $\mathrm{Mg} \mathrm{m}^{-3}$, respectivamente) (Figura 1a) e, numa tendência coerente, um dos maiores valores de macroporosidade na camada de $5-10 \mathrm{~cm}\left(0,19 \mathrm{~m}^{3} \mathrm{~m}^{-3}\right)$ e o maior na camada de 10-20 $\mathrm{cm}\left(0,18 \mathrm{~m}^{3} \mathrm{~m}^{-3}\right)$ (Figura 1b). Assim como na camada superficial do solo sob aveia e ervilhaca, essa menor densidade do solo e maior macroporosidade em 5-10 e 10-20 cm foram consequência da ação do sistema radicular, no caso da alfafa, pois a ação mecânica de crescimento tanto radial como longitudinal de suas raízes favorece a formação de poros e canais no solo (Meek et al., 1989; Rasse et al., 2000). Isso não significa, porém, que raízes de alfafa tiveram papel menos importante nos resultados de densidade do solo e macroporosidade na camada de $0-5 \mathrm{~cm}$, onde as melhores condições foram observadas em Av-Mi-Tr-So e Er-Mi-Tr-So.

Em profundidade, houve tendência geral de aumento da densidade do solo (Figura 1a) e de redução da macroporosidade (Figura 1b). No entanto, nenhum valor de macroporosidade foi inferior a $0,10 \mathrm{~m}^{3} \mathrm{~m}^{-3}$, geralmente considerado como crítico, abaixo do qual ocorrem restrições em termos 

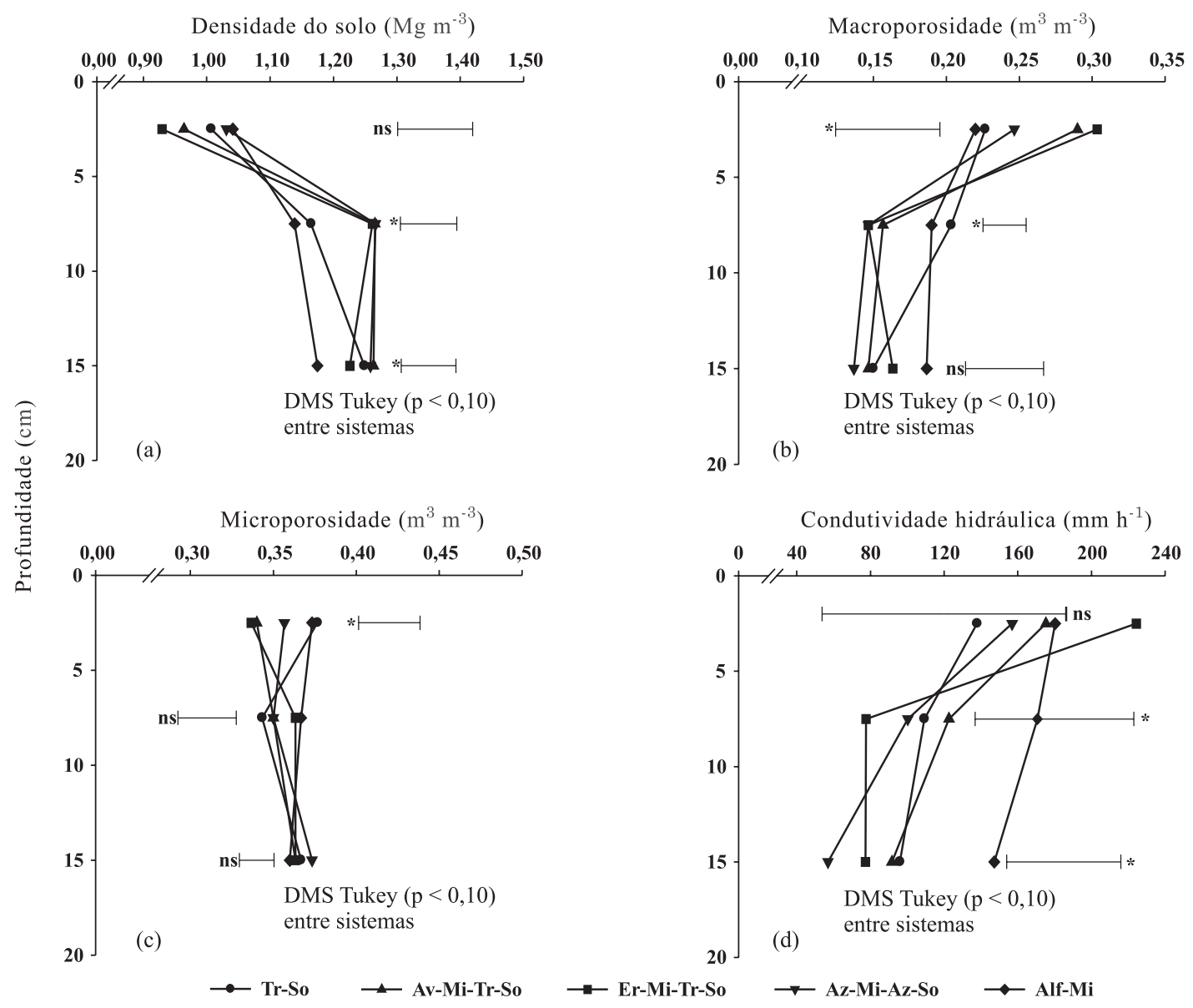

Figura 1. Densidade do solo (a), macroporosidade (b), microporosidade (c) e condutividade hidráulica saturada (d) de um Latossolo Vermelho sob sistemas de culturas em plantio direto, nas camadas de 0-5, 5-10 e 10-20 cm. Tr-So: trigo-soja; Av-Mi-Tr-So: aveia-milho-trigo-soja; Er-Mi-Tr-So: ervilhacamilho-trigo-soja; Az-Mi-Az-So: azevém-milho-azevém-soja; Alf-Mi: alfafa-milho. Barras horizontais representam a diferença mínima significativa pelo teste de Tukey $(p<0,10)$ (ns: não significativo; *: Significativo a $10 \%$ ).

de difusão de oxigênio para as raízes (Reichert et al., 2004).

A microporosidade na camada de $0-5 \mathrm{~cm}$ foi maior nos sistemas Tr-So $\left(0,38 \mathrm{~m}^{3} \mathrm{~m}^{-3}\right)$ e Alf-Mi $\left(0,37 \mathrm{~m}^{3} \mathrm{~m}^{-3}\right)$ e menor nos sistemas Er-Mi-Tr-So $\left(0,34 \mathrm{~m}^{3} \mathrm{~m}^{-3}\right)$ e Av-Mi-Tr-So $\left(0,34 \mathrm{~m}^{3} \mathrm{~m}^{-3}\right)$ (Figura 1c), evidenciando tendência aproximadamente inversa à observada na macroporosidade (Figura 1b) e direta à observada para a densidade (Figura 1a). Isso, de certa forma, pode significar menor disponibilidade de água na camada superficial do solo sob aveia ou ervilhaca, uma vez que a maior macroporosidade acaba diminuindo a microporosidade. Nas camadas de 5-10 cm e 10-20 cm, não houve tendência e diferenças significativas entre os sistemas, ficando os valores médios de microporosidade em 0,35 e $0,37 \mathrm{~m}^{3} \mathrm{~m}^{-3}$, respectivamente.

A condutividade hidráulica saturada na camada superficial não diferiu significativamente, apesar da tendência de o sistema Er-Mi-Tr-So apresentar maior valor (224 $\mathrm{mm} \mathrm{h}^{-1}$ ) (Figura 1d). O sistema Alf-Mi foi o que possibilitou maior condutividade hidráulica nas camadas de $5-10\left(170 \mathrm{~mm} \mathrm{~h}^{-1}\right)$ e 10


de macroporosidade e com possíveis efeitos benéficos em termos de infiltração de água no solo e redução de escoamento superficial. Rasse et al. (2000) também já haviam destacado o papel da alfafa em melhorar a estrutura do solo ao relatarem aumento de $57 \%$ na condutividade hidráulica saturada do solo sob alfafa, em comparação ao solo em pousio. Esses autores atribuíram o aumento na condutividade ao aumento na porosidade, decorrente, principalmente, da maior amplitude dos ciclos de umedecimento e secamento do solo e das altas taxas de renovação (turnover) das raízes de alfafa (Rasse et al., 2000).

Os resultados de condutividade hidráulica apresentaram estreita correlação com a macroporosidade 
(Figura 2), o que é entendido como coerente, pois o mesmo sistema de poros e canais que constituem a macroporosidade também é responsável pela permeabilidade da água em condições saturadas (Rasse et al., 2000).

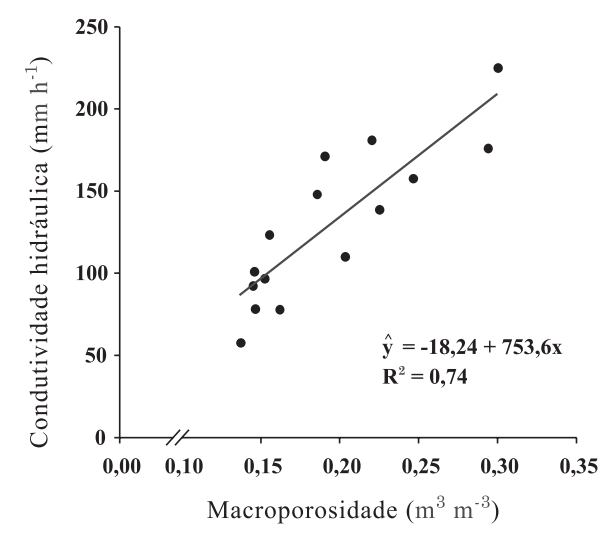

Figura 2. Relação entre macroporosidade e condutividade hidráulica saturada de um Latossolo Vermelho sob sistemas de culturas em plantio direto, considerando as camadas de 0-5, 5-10 e 10-20 cm.

\section{Agregação do solo}

O diâmetro médio ponderado úmido $(\mathrm{DMPu})$ dos agregados da camada de $0-5 \mathrm{~cm}$ variou de 2,39 mm no sistema Er-Mi-Tr-So para 3,04 mm no sistema Tr-So e tendeu a aumentar em profundidade (Figura 3). Embora as diferenças não tenham sido significativas nas camadas de $0-5$ e $5-10 \mathrm{~cm}$, houve correlação direta e estreita entre DMPu e densidade do solo (Figura 4), evidenciando a possibilidade de que a estabilidade desses agregados em água seja também resultado do processo de compressão do solo promovido pelo tráfego de máquinas, o que não pode ser necessariamente entendido como algo positivo. Carpenedo \& Mielniczuk (1990) observaram, para um Latossolo Vermelho distroférrico, que agregados do solo sob plantio direto na sucessão trigo-soja apresentaram-se compactados e com o predomínio de microporos, em relação aos agregados de solo sob pastagem perene e com maior abundância de raízes.

Para amostras com maior densidade de raízes - como Er-Mi-Tr-So e Av-Mi-Tr-So na camada de 0-5 cm e Alf-Mi nas camadas de 5-10 e 10-20 cm constatou-se visualmente que elas eram facilmente desagregadas durante a manipulação e remoção para a passagem em peneira de $8,00 \mathrm{~mm}$. O resultado disso foi a tendência de menor $\mathrm{DMPu}$ para esses sistemas e camadas (Figura 3), o que de certa forma contradiz os trabalhos que relatam a contribuição de raízes em formar agregados estáveis de maior diâmetro (Paladini \& Mielniczuk, 1991; Campos et al., 1995; Wohlenberg et al., 2004). Uma hipótese para explicar a redução no $\mathrm{DMPu}$ pela maior abundância de raízes pode ser baseada na fragmentação de agregados maiores em menores por planos de fraqueza formados durante os ciclos de

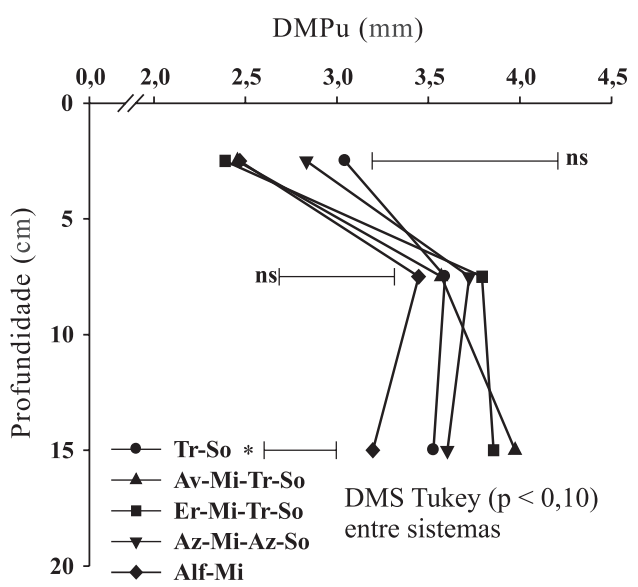

Figura 3. Diâmetro médio ponderado úmido (DMPu) de agregados de um Latossolo Vermelho sob sistemas de culturas em plantio direto, nas camadas de 0-5, 5-10 e 10-20 cm. Tr-So: trigosoja; Av-Mi-Tr-So: aveia-milho-trigo-soja; Er-Mi-Tr-So: ervilhaca-milho-trigo-soja; AzMi-Az-So: azevém-milho-azevém-soja; Alf-Mi: alfafa-milho. Barras horizontais representam a diferença mínima significativa pelo teste de Tukey $(p<0,10)$ (ns: não significativo; *: Significativo a $10 \%$ ).

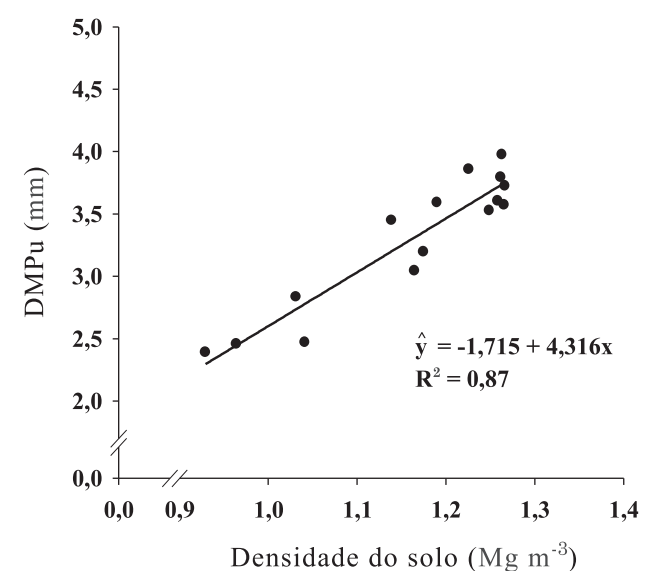

Figura 4. Relação entre densidade do solo e diâmetro médio ponderado úmido (DMPu) de agregados de um Latossolo Vermelho sob sistemas de culturas em plantio direto, considerando as camadas de 0-5, 5-10 e 10-20 cm. 
umedecimento-secamento que ocorrem na rizosfera, ao longo de eventos de precipitação pluvial seguidos por absorção de água pelas raízes (Bradfield, 1937; Rasse et al., 2000). Isso forma uma estrutura grumosa e, no entanto, não deve necessariamente ser entendido como algo desvantajoso, pois essa fragmentação produz macroporos responsáveis pela aeração e condutividade hidráulica saturada, como visto anteriormente. Além disso, no solo a unidade estrutural é mantida, pois as raízes continuam desempenhando seu papel de enredamento de unidades estruturais maiores que $8,00 \mathrm{~mm}$ - uma escala de estrutura do solo que não foi considerada neste estudo, pois os agregados foram manualmente quebrados em unidades menores e as raízes removidas.

\section{Resistência mecânica do solo à penetração (RP)}

Em geral, para todos os sistemas, os maiores valores de $\mathrm{RP}$ ocorreram aos 12,5 ou $15,0 \mathrm{~cm}$ de profundidade, e os menores, até 5,0 ou $7,5 \mathrm{~cm}$ (Figura 5). Esse padrão de comportamento da RP ao longo do perfil do solo é resultante da aplicação de cargas de rodado na superfície e da ação de fatores que aliviam o efeito dessas cargas. O padrão de distribuição de pressão abaixo do rodado é de tal forma que a pressão diminui a partir da superfície do solo para as camadas mais profundas (Hakansson et al.,

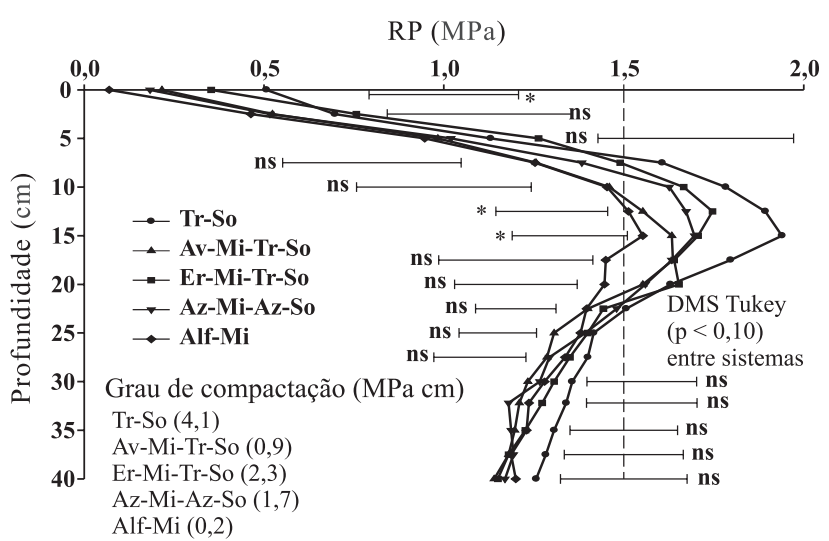

Figura 5. Resistência mecânica do solo à penetração (RP) e grau de compactação de um Latossolo Vermelho sob sistemas de culturas em plantio direto. Tr-So: trigo-soja; Av-Mi-Tr-So: aveiamilho-trigo-soja; Er-Mi-Tr-So: ervilhacamilho-trigo-soja; Az-Mi-Az-So: azevém-milhoazevém-soja; Alf-Mi: alfafa-milho. Barras horizontais representam a diferença mínima significativa pelo teste de Tukey $(p<0,10)$ (ns: não significativo; *: Significativo a $10 \%$ ). O grau de compactação (MPa cm) é dado pela integração da área do gráfico que possui RP superior a 1,5 MPa, considerado como crítico.
1988). O mesmo era de se esperar para o padrão de distribuição da RP. Entretanto, na camada de 0-7,5 cm a RP foi baixa, devido ao efeito de alívio causado pela maior abundância de raízes e ao efeito de elementos sulcadores e discos de semeadoras, que promovem mobilização mais intensa até os $7,5 \mathrm{~cm}$. Esse padrão de comportamento da RP também foi observado num Latossolo Vermelho argiloso sob vários sistemas de rotação de culturas, onde o maior estado de compactação foi obtido em torno de $10 \mathrm{~cm}$ e o menor, até $7 \mathrm{~cm}$ de profundidade (Genro-Junior et al., 2004). O menor estado de compactação na camada superficial também foi atribuído à mobilização do solo nas operações de semeadura e adubação em linha (Genro-Junior et al., 2009). Num trabalho de revisão, Reichert et al. (2004) concluíram que, geralmente, a camada de maior compactação no plantio direto situa-se entre 8 e $15 \mathrm{~cm}$.

Entre os sistemas de culturas, a maior RP foi observada na sucessão Tr-So, com valores superando o crítico de $1,5 \mathrm{MPa}$ na camada de 7,5 a $22,5 \mathrm{~cm}$ (Figura 5). O sistema semiperene Alf-Mi foi o que apresentou a menor RP, com valores abaixo do crítico em praticamente todo o perfil avaliado (Figura 5). Os demais sistemas apresentaram comportamento intermediário. Com base nesses resultados de RP e sua distribuição ao longo do perfil, calculou-se o grau de compactação do solo, que foi maior no sistema Tr-So (4,1 $\mathrm{MPa} \mathrm{cm})$ e praticamente nulo no sistema Alf-Mi (0,2 MPa cm) (Figura 5). Como já discutido, a menor intensidade de tráfego de máquinas, a ação mais eficaz das raízes da alfafa em estruturar o solo, seja por ação de polissacarídeos exsudados na forma de mucilagens (Reid \& Goss, 1981) ou pela abertura de canais (Meek et al., 1989), e o maior teor de matéria orgânica (Santos et al., 2011) são as possíveis explicações para o sistema Alf-Mi apresentar o menor estado de compactação. O contrário disso foi a situação, possivelmente, ocorrida no sistema Tr-So.

A tendência geral de aumento da densidade do solo até a camada de 10-20 cm (Figura 1a) é coerente com os dados de RP, até $20 \mathrm{~cm}$ de profundidade, razão pela qual essas variáveis apresentaram relação direta entre si (Figura 6), confirmando observações prévias em outros estudos (GenroJunior et al., 2004; Reichert et al., 2004; Secco et al., 2004). Com essa relação e considerando o valor crítico de 1,5 MPa de RP, deduz-se que a densidade crítica para esse solo seja de $1,25 \mathrm{Mg} \mathrm{m}^{-3}$, abaixo de $1,55 \mathrm{Mg} \mathrm{m}^{-3}$, proposto por Reichert et al. (2004) para solos com textura média (200 a $500 \mathrm{~g} \mathrm{~kg}^{-1}$ de argila). Para a macroporosidade, a relação com RP (Figura 7) indica que a macroporosidade crítica seria de $0,15 \mathrm{~m}^{3} \mathrm{~m}^{-3}$, ou seja, acima do valor de $0,10 \mathrm{~m}^{3} \mathrm{~m}^{-3}$, geralmente proposto como o crítico (Reichert et al., 2004). 


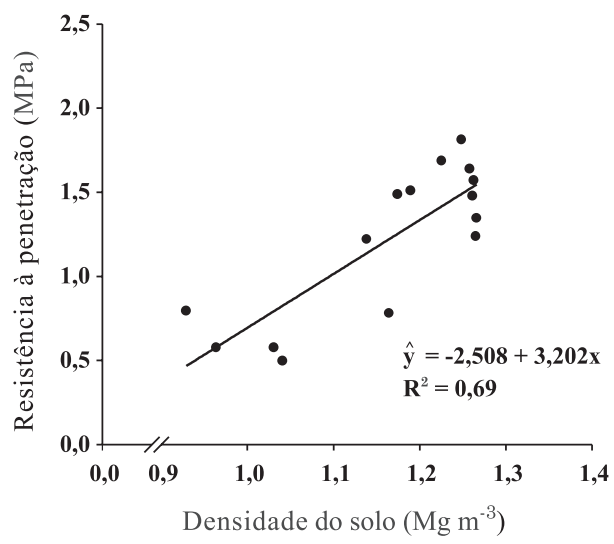

Figura 6. Relação entre densidade do solo e resistência mecânica do solo à penetração (RP) de um Latossolo Vermelho sob sistemas de culturas em plantio direto, considerando as camadas de 0-5, 5-10 e 10-20 cm. Para adequar os dados de RP nas camadas analisadas, foi realizada uma média da seguinte forma: a) camada de 0-5 cm - utilizaram-se os valores das profundidades de 0,0, 2,5 e 5,0 cm; b) camada de 5-10 cm - valores das profundidades de 5,0, 7,5 e 10,0 cm; e c) camada de 10-20 cm - valores das profundidades de 10,0, 12,5, 15,0, 17,5 e 20,0 cm.

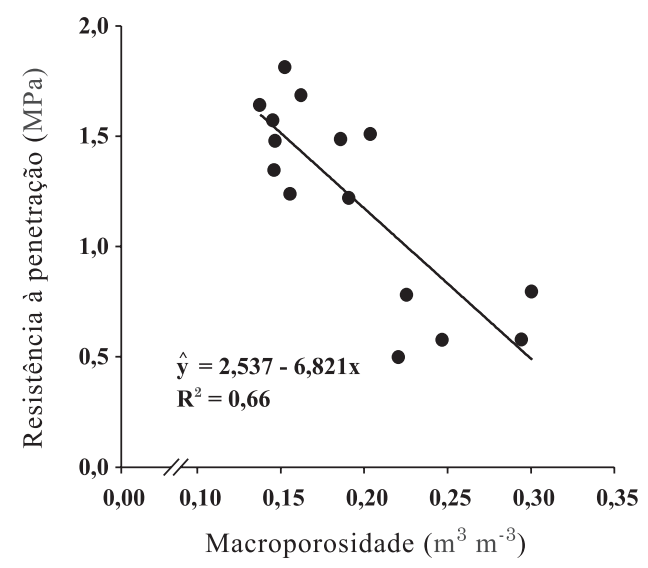

Figura 7. Relação entre macroporosidade e resistência mecânica do solo à penetração de um Latossolo Vermelho sob sistemas de culturas em plantio direto, considerando as camadas de 0-5, 5-10 e 10-20 cm. Para adequar os dados de RP nas camadas analisadas, foi realizada uma média da seguinte forma: a) camada de 0-5 cm - utilizaram-se os valores das camadas de $0,0,2,5$ e $5,0 \mathrm{~cm}$; b) camada de 5-10 cm - valores das camadas de 5,0, 7,5 e $10,0 \mathrm{~cm}$; e c) camada de 10-20 cm - valores das camadas de $10,0,12,5,15,0,17,5$ e $20,0 \mathrm{~cm}$.

\section{CONCLUSÕES}

1. Considerando-se a camada de $0-20 \mathrm{~cm}$ como um todo, o sistema semiperene alfafa-milho possui maior capacidade para melhorar a estrutura do solo na região subtropical dos Campos Gerais do Paraná, por aumentar a macroporosidade e a condutividade hidráulica, em relação aos sistemas baseados em cultivos de espécies anuais.

2. Sistemas bianuais de rotação, baseados em plantas de cobertura como aveia-preta ou ervilhaca, possuem maior capacidade de promover melhorias na qualidade estrutural do solo, em comparação com a sucessão trigo-soja.

3. Essas melhorias estruturais trazem implicações positivas tanto ao crescimento radicular, pela menor resistência mecânica do solo à penetração e maior aeração, quanto à qualidade ambiental, por supostamente aumentar a taxa de infiltração de água e diminuir o escoamento superficial.

\section{AGRADECIMENTOS}

À CAPES, pela concessão das bolsas de mestrado (V.L. Da-Silva e J.E. Mellek). Ao CNPq, pelo apoio financeiro (processo 477400/2007-8 - Edital Universal 15/2007) e pela concessão das bolsas PQ (J. Dieckow e N. Favaretto). À Fundação Araucária, pelo apoio financeiro (convênio 57/2007 UFPR, protocolo 9496). À equipe de campo da Fundação $\mathrm{ABC}$. Ao acadêmico Maico Pergher e à laboratorista Elda Lubasinski, pela ajuda nas atividades de campo e laboratório.

\section{LITERATURA CITADA}

ALBUQUERQUE, J.A.; REINERT, D.J.; FIORIN, J.E.; RUEDELL, J.; PETRERE, C. \& FONTINELLI, F. Rotação de culturas e sistemas de manejo do solo: Efeito sobre a forma da estrutura do solo ao final de sete anos. R. Bras. Ci. Solo, 19:115-119, 1995.

ANDRADE, A.P.; MAFRA, A.L.; BALDO, G.R.; PICCOLLA, C.D.; BERTOL, I. \& ALBUQUERQUE, J.A. Physical properties of a Humic Cambisol under tillage and cropping sistems after 12 years. R. Bras. Ci. Solo, 34:219-226, 2010.

BERTOL, I.; ALBUQUERQUE, J.A.; LEITE, D.; AMARAL, A.J. \& ZOLDAN-JUNIOR, W.A. Propriedades físicas do solo sob preparo convencional e semeadura direta em rotação e sucessão de culturas, comparadas às do campo nativo. R. Bras. Ci. Solo, 28:155-163, 2004.

BRADFIELD, R. Soil conservation from the viewpoint of soil physics. J. Am. Soc. Agron., 29:85-92, 1937.

CAMPOS, B.C.; REINERT, D.J.; NICOLODI, R.; RUEDELL, J. \& PETRERE, C. Estabilidade estrutural de um Latossolo Vermelho-Escuro distrófico após sete anos de rotação de culturas e sistemas de manejo de solo. R. Bras. Ci. Solo, 19:121-126, 1995. 
CANTERI, M.G.; ALTHAUS, R.A.; VIRGENS-FILHO, J.S.; GIGLIOTI, E.A. \& GODOY, C.V. SASM-AGRI - Sistema para análise e separação de médias em experimentos agrícolas pelos métodos Scott-Knott, Tukey e Duncan. R. Bras. Agrocomp., 1:18-24, 2001.

CARPENEDO, V. \& MIELNICZUK, J. Estado de agregação e qualidade de agregados de Latossolos Roxos, submetidos a diferentes sistemas de manejo. R. Bras. Ci. Solo, 14:99$105,1990$.

CINTRA, F.L.D. \& MIELNICZUK, J. Potencial de algumas espécies vegetais para a recuperação de solos com propriedades físicas degradadas. R. Bras. Ci. Solo, 7:197201, 1983.

EMPRESA BRASILEIRA DE PESQUISA AGROPECUÁRIA EMBRAPA. Manual de métodos de análise de solos. 2.ed. Rio de Janeiro, Centro Nacional de Pesquisa de Solos, 1997. 212p.

EMBRAPA \& FUNDAÇÃO-ABC. Mapa do levantamento semidetalhado de solos: Município de Castro. Castro, Fundação ABC, 2001.

GENRO-JUNIOR, S.A.; REINERT, D.J. \& REICHERT, J.M. Variabilidade temporal da resistência à penetração de um Latossolo argiloso sob semeadura direta com rotação de culturas. R. Bras. Ci. Solo, 28:477-484, 2004.

GENRO-JUNIOR, S.A.; REINERT, D.J.; REICHERT, J.M. \& ALBUQUERQUE, J.A. Atributos físicos de um Latossolo Vermelho e produtividade de culturas cultivadas em sucessão e rotação. Ci. Rural, 39:65-73, 2009.

GREENLAND, D.J. Changes in the nitrogen status and physical condition of soils under pastures, with special reference to the maintenance of the fertility of Australian soils used for growing wheat. Soils Fert., 34:237-251, 1971.

HAKANSSON, I.; VOORHEES, W.B. \& RILEY, H. Vehicle and wheel factors influencing soil compaction and crop response in different traffic regimes. Soil Tillage Res., 11:239-282, 1988.

IAPAR. Cartas Climáticas do Estado do Paraná 1984. Londrina, 1984. 49p.

KEMPER, W.D. \& ROSENAU, R.C. Aggregate stability and size distribution. In: KLUTE, A., ed. Methods of soil analysis. Physical and mineralogical methods. 2.ed. Madison, SSSA, 1986. Part 1.p.425-442.

KLEIN, V.A. \& CAMARA, R.K. Rendimento da soja e intervalo hídrico ótimo em Latossolo Vermelho sob plantio direto escarificado. R. Bras. Ci. Solo, 31:221-227, 2007.

MEEK, B.D.; RECHEL, E.A.; CARTER, L.M. \& DETAR, W.R. Changes in infiltration under alfalfa as influenced by time and wheel traffic. Soil Sci. Soc. Am. J., 53:238-241, 1989.

OLIVEIRA, L.B. Determinação da macro e microporosidade pela "mesa de tensão" em amostras de solo com estrutura indeformada. Pesq. Agropec. Bras., 3:197-200, 1968.
PALADINI, F.L.S. \& MIELNICZUK, J. Distribuição de tamanho de agregados de um solo Podzólico Vermelho-Escuro afetado por sistema de culturas. R. Bras. Ci. Solo, 15:135-140, 1991.

RASSE, D.P.; SMUCKER, A.J.M. \& SANTOS, D. Alfalfa root and shoot mulching effects on soil hydraulic properties and aggregation. Soil Sci. Soc. Am. J., 64:725-731, 2000.

REICHERT, J.M.; REINERT, D.J. \& SILVA, V.R. Compactação do solo em sistema de plantio direto: Limites críticos e mitigação. In: COUTO, E.G. \& BUENO, J.F., eds. Os (des) caminhos do uso da água na agricultura brasileira. Cuiaba, UFMT, 2004. p.167-198.

REID, J.B. \& GOSS, M.J. Effect of living roots of different plantspecies on the aggregate stability of two arable soils. J. Soil Sci., 32:521-541, 1981.

SANTOS, N.Z.; DIECKOW, J.; BAYER, C.; MOLIN, R.; FAVARETTO, N.; PAULETTI, V. \& PIVA, J.T. Forages, cover crops and related shoot and root additions in no-till rotations to $\mathrm{C}$ sequestration in a subtropical Ferralsol. Soil Tillage Res., 111:208-218, 2011.

SECCO, D.; REINERT, D.J.; REICHERT, J.M. \& DA ROS, C.O. Produtividade de soja e propriedades físicas de um Latossolo submetido a sistemas de manejo e compactação. R. Bras. Ci. Solo, 28:797-804, 2004.

SILVA, I.F. \& MIELNICZUK, J. Avaliação do estado de agregação do solo afetado pelo uso agrícola. R. Bras. Ci. Solo, 21:313-319, 1997.

TAYLOR, H.M.; ROBERSON, G.M. \& PARKER, J.J. Soil strength-root penetration relations for medium- to Coarsectextured soil materials. Soil Sci., 102:18-22, 1966.

TISDALL, J.M.; COCKROFT, B. \& UREN, N.C. The stability of soil aggregates as affected by organic materials, microbial activity and physical disruption. Austr. J. Soil Res., 16:917, 1978.

TISDALL, J.M. \& OADES, J.M. Stabilization of soil aggregates by the root systems of ryegrass. Austr. J. Soil Res., 17:429$441,1979$.

TISDALL, J.M. \& OADES, J.M. Organic matter and water-stable aggregates in soils. J. Soil Sci., 33:141-163, 1982.

TORMENA, C.A.; DA SILVA, A.P. \& LIBARDI, P.L. Soil physical quality of a Brazilian Oxisol under two tillage systems using the least limiting water range approach. Soil Tillage Res., 52:223-232, 1999.

VEZZANI, F.M. \& MIELNICZUK, J. Agregação e estoque de carbono em Argissolo submetido a diferentes práticas de manejo agrícola. R. Bras. Ci. Solo, 35:213-223, 2011.

WOHLENBERG, E.V.; REICHERT, J.M.; REINERT, D.J. \& BLUME, E. Dinâmica da agregação de um solo francoarenoso em cinco sistemas de culturas em rotação e sucessão. R. Bras. Ci. Solo, 28:891-900, 2004. 